\title{
THE ROLE OF ETHICAL LEADERSHIP AND WHISTLEBLOWING INTENTIONS: MEDIATING APPARATUS OF MORAL IDENTITY
}

\author{
Adnan Ismail \\ MS Department of Business Administration \\ Senior Customer Service Officer \\ NRSP Microfinance Bank, Abdul-Hakeem Branch, Pakistan \\ E-mail: adnanismail752@gmail.com \\ K. M. Anwarul Islam \\ Associate Professor \\ Department of Business Administration \\ The Millennium University, Dhaka, Bangladesh \\ E-mail: ai419bankingdu@gmail.com \\ Muhammad Zohaib \\ MS Department of Business Administration \\ Lecturer \\ Superior Group of Colleges, Multan, Pakistan \\ E-mail: muhammadzohaib4647@gmail.com \\ Sana Tasaduq \\ Bachelor of Commerce \\ Bahauddin Zakariya University, Multan, Pakistan \\ E-mail: sanatasaduq29155@gmail.com \\ Muhammad Ismail \\ MS/M.Phil. Business Administration \\ Caretaker Officer: CM House. Punjab, Pakistan \\ Adjunct faculty member: (Project and Operation Management Dpt.) \\ The Islamiya University of Bahawalpur, Punjab, Pakistan \\ E-mail: ismailleghari14@gmail.com
}

\begin{abstract}
Separation of strategic approaches and morals prompted various business outrages and untrustworthy practices in working environments. This encouraged researchers and practice holders to examine significance of ethical quality at work environment. In particular, the job that moral chiefs play in advancing positive representative practices is urgent. This examination article has featured the part of moral innovators in molding whistleblowing goals of their subordinates. Alongside, this exploration article has likewise researched the part of good character. An aggregate of four speculations, analyzing the immediate impact of moral initiative on moral personality and whistleblowing expectations and meditational job of good character
\end{abstract}


were proposed. This exploration article embraced a period slacked research article plan and gathered data from representative friend dyads at three focuses on schedule. Number of respondents was 214; Cross-sectional technique was used for data collection. Respondents were selected from different services organizations from Multan. Data was analysed on SPSS and AMOS. Results were obtained by applying reliability test, ANOVA, Correlation test, and regression test by using PROCESS Macro. Results gained verified that the role of ethical leaders in shaping moral identity of employees as well as their whistleblowing intentions. The findings suggest that employees working under ethical leaders are inclined to stand up against malevolent and unethical practices taking place at their workplace. Thus, organizations must hire leaders with higher ethical inclinations and also train the existing leaders about importance of ethics. Moreover, this research article has highlighted multiple avenues for future research.

Keywords: Ethical Leadership, Moral Identity, Whistleblowing Intentions, Identity, Social Identity Theory.

\section{INTRODUCTION}

Leaders can influence self-concept of followers such that they can alter or modify the way their subordinates see or define themselves, Brown et al. (2006), Aquino and Reed (2002) defined moral identity as "a self-conception organized around a set of moral traits" or one can assume it as certain features/facets of identity that are concerned with ethical norms and values. Research has shown that those who possess a stronger moral identity have greater tendency of acting ethically/morally, Patrick et al. (2018). Ethical leaders use their managerial skill and moral principles in influencing and directing the behaviours of their employees by guiding them with ethical actions, Miceli et al., (1985). Ethical leader shapes the moral identity of their followers due to their own ethical and moral values, Mayer et al. (2012).

Researches shows that whistle blowing intensions will be enhanced in the presence of ethical environment in the organizations, Dalton and Radtke (2013). Ethical leaders provide them with the necessary psychological safety and employees judge it supportive and worthwhile to speak up against immoral practices in ethical environment created by ethical leaders, Tu, $\mathrm{Lu}$, Choi, and Guo (2019); Walumbwa and Schaubroeck (2009). Thus, staff functional under ethical leader are inclined to develop a strong link with their organization as well as other people at work, Brown et al. (2006), and foster sturdier identification with both the principal actor i.e., the leader as well as the organization which will increase their voice and whistle blowing behaviours at work, Walumbwa and Schaubroeck (2009).

One of the prime factors that can result in positive outcomes at workplace is leadership such that leaders play a noteworthy role in sculpting, encouraging and promoting pro-social and constructive/moral voice of employees working under them, Grojean et al. (2004). Role of leadership in affecting and influencing subordinates and organizations cannot be denied. Precisely, ethical leaders can oblige as role model for their aides who may encourage as well as force them to act ethically and morally. Ethical leaders set clear moral standards and convey them such that employees are motivated to report any wrongdoing which gives rise to whistle blowing behaviours, Brown et al. (2006).

\section{Gap Analysis \& Problem Statement}

Reviewing research on ethical leadership, pointed out that a number of research areas are there that should be explored by future researchers specifically, they said that future researchers must incorporate new intervening variables between ethical leadership and outcomes. And also 
comprehend role of contextual factors in research article in this leadership style. Same suggestions were given by Saha et al. (2019) and researchers were encouraged to survey the domain of ethical leadership and its effect on various organizational outcomes.

An integrative review on ethical leadership by Lemoine et al. (2019) calls scholars to observe the underlying links between ethical leadership and its aftermaths. They highlighted that a broad range of mediators and moderators should be linked with ethical leadership and outcomes. So, recognizing the moderators as well as effects of ethical leadership is a worthy area for research Miceli et al. (1985), propose that there is need to investigate new mediating components between morality and worker's positive practices. Also, specialists intermittently call for further exploring the connections among leadership and whistleblowing, Bhal et al. (2019), Liu et al. (2015). Management scholars contend that that there is a need to explore the positive results of ethical leader for organizations and its stakeholders, O'Keefe, Messervey, and Squires (2018). Whistleblowing activities are pro-social activities as they mean to serve the organizations; along these lines this examination is clarifying the part of ethical leaders in forming whistleblowing intentions of workers.

Ferreira (2017) argued that the intervening variables amongst leadership styles i.e. ethical leadership and individual level outcomes should be investigated. In particular, May, Chang and Callahan et al. (2000), vied scholars to explore the role of individuals' morality along with other variables against moral issues at work and how do employees deal with them in future investigations. Besides, search on whistleblowing argues that moral identity as an important individual level factor should be incorporated into research endeavours. Thus, this research is research article mediating role of moral identity in the relationship between ethical leadership and outcomes. Simply, this research article is contemplating intervening part of moral identity in a relationship between leader's ethical/moral conduct and whistleblowing intents of subordinates.

Leaders are imperative for organizations as they can shape thoughts, behaviours and perceptions of their followers, Yukl and Chavez (2002). Though, ethical leadership has been extensively studied in management literature, yet a number of queries regarding their impact on employee behaviours and attitudes are left unanswered, Ouakouak, Zaitouni, and Arya (2020); Zhou et al. (2020). Therefore, researchers argue that with regards to ethical leadership there are various inquiries that should be replied, as highlighted in gap analysis section. Explicitly the significance of these leaders/managers in moulding subordinate's moral identity and authorizing whistleblowing is a domain that demands exploration. The motivation behind this inspection is to verify that how ethical leadership will influence moral character which impacts their extra-role yet beneficial practice i.e. whistleblowing intentions. It will likewise discover that whether Ethical leadership will elevate the worker's whistle blowing intentions through individual-level mechanism like moral identity.

\section{Research Questions}

- Does ethical leadership affect moral identity of employees?"

- "Do ethical leaders effect whistleblowing intentions of employees?"

- "Does moral identity effect whistleblowing intentions of employees?"

- "Does moral identity mediate the relationship between ethical leadership and whistleblowing intentions?" 


\section{Objectives of this Research}

The objectives are to examine the impact of ethical leadership on employee whistleblowing intentions. This research anticipates highlighting the role of ethical leaders in shaping moral selfconception and whistleblowing intentions of subordinates. Hence the objectives can be characterized as:

- To determine the impact of ethical leadership on moral identity

- To determine the impact of ethical leadership on whistleblowing intentions of employees

- To determine the impact of moral identity on whistle blowing intentions.

- To determine the mediating role of moral identity between ethical leadership and whistleblowing intentions

\section{Variable's Explanation}

- Ethical Leadership is defined as "the demonstration of normatively appropriate conduct through personal actions and interpersonal relationships, and the promotion of such conduct to followers through two-way communication, reinforcement and ethical decision making", Brown and Trevino (2006). Followers of these leaders are highly satisfied with their jobs and least stressed and exhausted, Sharif and Scandura (2014).

- Moral Identity is defined as "a self-schema/self-definition structured around a set of moral traits", Aquino and Reed (2002). Moral attributes, for example, being caring, reasonable, hard - working, and accommodating makes moral identity of an entity/person, Aquino et al. (2011). Heightened moral identity spurs moral action.

- Whistleblowing Intentions are characterized as "the individual's probability of actually engaging in whistle-blowing behavior", Chiu (2002). Where whistleblowing refers to disclosure of any unethical/immoral act to the higher authorities, for rectifying those actions.

\section{Ethical Leadership}

\section{LITERATURE REVIEW}

The ethical parts of ethical leadership centres around trustworthiness, genuineness, and judicious and principled basic leadership, Eubank, Christensen-Salem et al. (2020). People learn from their leaders by watching those actions which are practiced repeatedly, what is compensated or acknowledged and what conduct prompts correction/punishment. An ethical leader does this through 'role modelling' which refers to demonstrating the right conduct by oneself, Yukl (2002). Ethical leader are otherwise called moral individuals and moral directors/managers. The individual impersonate or copy the approaches, qualities, and practices of their ethical leader, Brown and Trevino (2006). At the point when a leader shows ethics and morality through his own behaviour and relational influences then he/she is essentially doing ethical leadership, Sharif et al. (2014). His/her proactive efforts to persuade ethicality in subordinates and dissuade unethical behaviour encompass the moral manager dimension, Walumbwa et al. (2012). Ethical managers make ethical expression a part of their management schedule.

\section{Moral Identity}

Studies have proven that moral identity undoubtedly supports prosocial deeds such as philanthropy and dejects unethical behaviours including deception, Aquino and Reed (2002). Simply put, if individuals sense that ethical values together with being "honest", "compassionate", "truthful", and "generous" are significant for defining their identity, they've a 
sturdy moral identification. Being an ethical individual forms a desire to be consistent with one's ethical concepts thru which individuals are inspired to benefit independence from social conventions.

Identities are thought to generate motivation due to a choice for self-consistency or aversion to the cognitive dissonance of appearing opposite to at least one's self-idea. The motivation for moral energy in response to moral identity ascends from peoples' preference for self-consistency, Sharif et al. (2014). Simply, a person whose moral identity is self-important is innately driven to behave in ways and means that are constant with their information of how a moral person should be. As only a few factors of our universal self-ideas can be active at any individual time, there's an on-going competition among identities for stimulation. Higher the strength of one's moral identity for self-concept, higher is the probability of its activation and so stronger are the chances that one is to act morally, the activation of identities is dependent upon environmental stimulation so that moral prompts tend to spur moral identities while cues for selfinterest can displace moral identification. A positive connection of moral identity is found with ethical leader, Mayer et al. (2012), reasonable procedures and regulations, and negative connection with moral withdrawal and the possibility of unethical conduct in business matters. Ethical and socially applauded practices are spurred when moral identity is initiated. Moral attributes, for example, being caring, reasonable, and hard - working, and accommodating makes moral identity of an individual, Aquino et al. (2011). It appears to be of prime importance in any event as in the thought we have of ourselves as good specialists impacts the reasons we are arranged to see as huge, or ought to be arranged to see as critical for our decisions. This shows moral character is particular from a theoretical incentive to be advanced or regarded, or as for which examinations can be made. Or maybe, moral personality can be viewed as (comprised by) a lot of qualities or on the other hand auras which makes us approach matters in specific manners, including a mien to take certain qualities, alternatives or types of correlation into thought in any case, Sharif and Scandura (2014).

\section{Employee Whistleblowing Intention}

Whistleblowing is an act to expose the unlawful, corrupt or criminal practices of the organization or its members to entities (individuals or organizations) which are authorized to take any action against them, Miceli et al. (1985). Whistle can be blown by existing employees of the organization or its former employees. Whistle blowing is a significant authoritative conduct within the sight of a wrongdoing. Whistle blowing is exceptionally useful for organizations when the bad behaviour rises at the work environment, Callahan and Dworkin (2000). At the point when leaders shows conditions in which rules/regulations promote ethical conduct at exactly that point the approach of whistle blowing will be viable, Lewis (2002). There are two kinds of whistle blowing one is inner and other is outer whistle blowing. Blowing the whistle to the specialists or the general population outside of the organization is called as outside whistle blowing and blowing the whistle to people and administrators within an association is called as interior whistle blowing, Park et al. (2008).

Organizational members who witness offense in their workplace lean toward not to approach to unveil the bad behaviour and remain quiet because of hazardous and uncertainty components related with the whistleblowing conduct. Previously studios on whistleblowing has demonstrated that among the elements why workers hesitant to report the wrongdoing is dread of counters, notion that such exertion will be vain, fear of negative examinations, work misfortune, profession peril, and threat of continuous oppression, Miceli et al. (1985). 


\section{Social Identity Theory}

According to SIT (1985) proposed by Tajfel and Tumer (1985) people categorise themselves and others into numerous social groupings, such as administrative affiliation, religious connection, and age unit etc. SIT, Tajfel and Tumer (1985) states that self-concept is comprised of a "personal-identity" incorporating characteristics such as physical appearances/features skills, psychosomatic qualities etc., and "social-identity "covering relevant group taxonomies. Tajfel and Turner (1985) while proposing SIT state that individuals tend to maintain positive selfesteem and for that purpose, they strive to gain a positive social identity. At first individuals sort their environment in terms of groups (social categorization) they define themselves in terms of the society/organization/group they are a part of and count these referents as in-group whereas individuals not belonging to in-groups are out-group. These social groups provide individuals a sense of self in social world i.e., a way to define themselves (social identification). To maintain a positive self-concept individual, evaluate their in-groups positively and out-groups negatively (Social comparison).

\section{HYPOTHESIS DEVELOPMENT}

Hypothesis 1: "Ethical leadership is positively related to whistleblowing intentions"

Hypothesis 2: "Ethical leadership is positively related to moral identity"

Hypothesis 3: "Moral identity is positively related to whistleblowing intentions"

Hypothesis 4: "Moral identity will mediate the relationship between ethical leadership and whistle-blowing intentions"

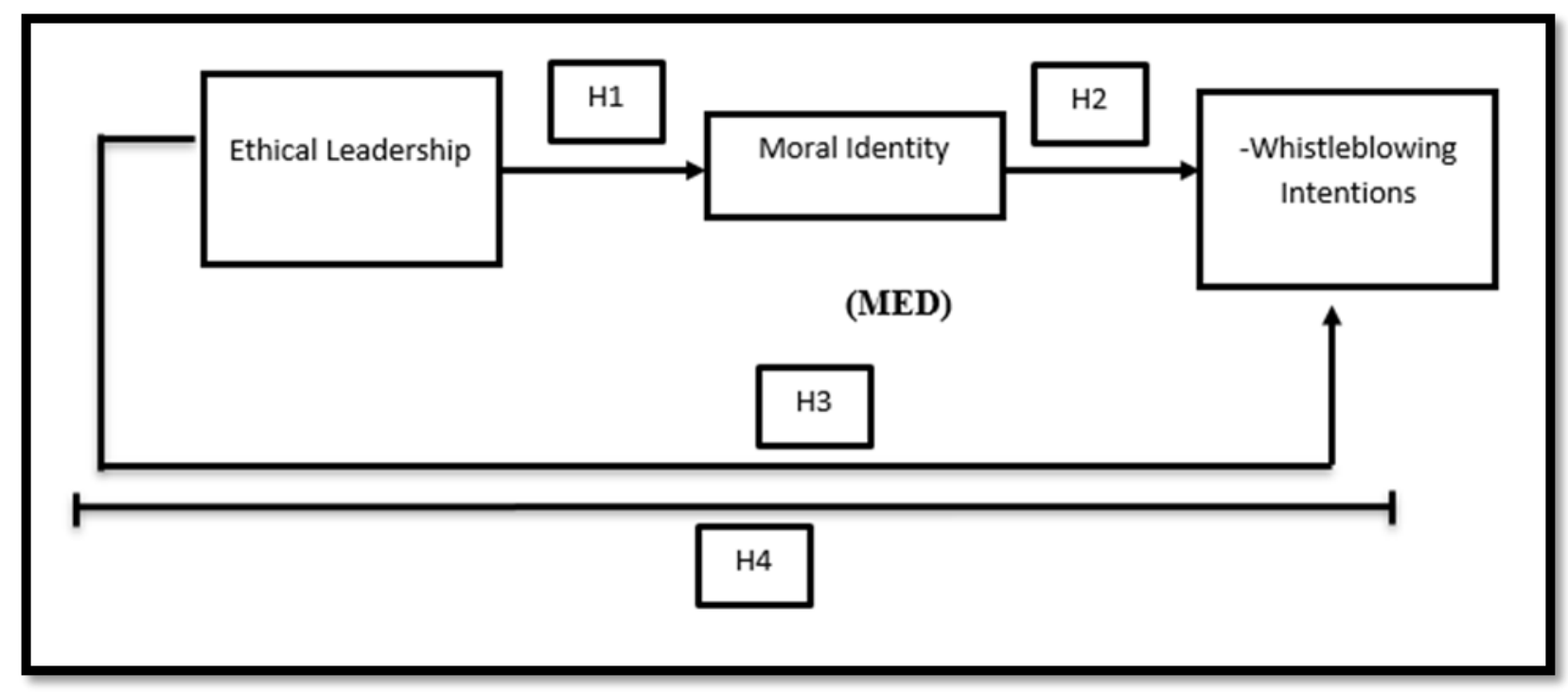

Figure 1. Framework

\section{RESEARCH METHODOLOGY}

This research accessed employees and their supervisor's/leaders in order to find employee responses on follower's moral identity, Whistle blowing, and their ethical leadership. Questionnaires comprised of measures of ethical leadership, moral identity and Whistle blowing intentions are used as a tool to receive feedback from the employees. 
In this research article, target population was employees working in telecom sector of Multan. Convenient sampling technique was used due to scarcity of time and resources. Respondents were accessed using personal and professional resources and participation in the research article was on voluntary basis. Along with a letter mentioning purpose and privacy of data was also attached with the questionnaire.

Respondents who provided data at time 1 were again contacted at time 2 and time 3 . They were instructed to provide a primary key so that their responses can be matched. 300 questionnaires were distributed at time1, 300 at T2 and 300 at T3. After matching the responses and discarding unusable responses a total of 214 responses were retrieved. Thus, the response rate of this research article is $71.3 \%$.

\section{Following Measures Are Used For Obtaining Data}

Ethical Leadership: To measure the Ethical Leadership (EL) scale developed by Wen, P., \& Chen (2016) is used (10 items). A sample item of Ethical leadership is: "My leader conducts his/her personal life in an ethical manner." Response is obtained from 7-point scale $(1=$ strongly disagree $-7=$ strongly agree). Cronbach alpha $=0.84$.

Moral Identity: A scale developed Aquino and Reed (2002) is used (10 items). Sample item includes: "I am committed to my moral principles". Response are obtained from 7-point scale 1 $=$ strongly disagree $-7=$ strongly agree). Cronbach alpha $=0.92$.

Whistle Blowing Intentions: To measure the Whistle blowing Park and Blenkinsopp's (2009) scale is used which consisted of four items. Sample item includes: "I would report it by using internal procedures". Response are obtained from 7-point scale $(1=$ strongly disagree $-7=$ strongly agree). Cronbach alpha $=0.89$.

The following table gives the instrument summary.

Table 1. Instrument Summary

\begin{tabular}{|l|c|l|c|}
\hline Variable & $\begin{array}{l}\text { No of } \\
\text { items }\end{array}$ & \multicolumn{1}{|c|}{ Sample item } & Cronbach alpha \\
\hline $\begin{array}{l}\text { Ethical } \\
\text { leadership }\end{array}$ & 10 & $\begin{array}{l}\text { "My leader has the best interests of employees } \\
\text { in mind" } \\
\text { "My leader conducts his/her personal life in an } \\
\text { ethical manner." }\end{array}$ & 0.84 \\
\hline Moral Identity & 10 & $\begin{array}{l}\text { "The kinds of books and magazines that I read } \\
\text { identify me as having these characteristics." }\end{array}$ & 0.92 \\
\hline $\begin{array}{l}\text { Whistleblowing } \\
\text { Intentions }\end{array}$ & 4 & $\begin{array}{l}\text { "I would report the issue to immediate } \\
\text { supervisor" } \\
\text { "I would report it to upper management" }\end{array}$ \\
\hline
\end{tabular}

\section{DATA ANALYSIS TOOLS \& PROCEDURE}

Data for this research article was gathered by using questionnaires, as described above. Selfadministered questionnaires were distributed to respondents. A cover letter explaining the scope and purpose of the research article is also attached. Moreover, respondents were ensured that their responses will remain confidential and will not be used for any other purpose except analysis. The obtained data was analysed to retrieve results by using SPSS and AMOS software. 
Specifically, preliminary analysis was performed in SPSS (descriptive, reliability, ANOVA, correlation). Whereas, CFA was performed in AMOS software. Moreover, to perform regression analysis PROCESS macro for SPSS was used.

Before proceeding, incomplete responses and unengaged responses were identified and discarded from further analysis as unengaged and incomplete responses tarnish the findings of the research article. After this step a set of 214 useable responses were retrieved. This data was gathered and coded in SPSS software. Then, initial analysis was performed such that missing values were identified and replaced with neutral values in data sheet. After that reliability analysis determined the reliability of instrument used. ANOVA was performed to identify control variables.

Moreover, Correlation analysis ensured discriminant validity and CFA in AMOS software ensured convergent validity of responses. At last, regression analysis was done to test the main effect and mediation hypothesis. To perform regression analysis, PROCESS by Preacher and Hayes macro was used. Detailed results obtained are discussed in the following sections.

\section{Confirmatory Factor Analysis}

CFA yielded factor loadings along with model fit indices. The regression score weights of all items were greater than 0.3 , hence all items loaded distinctly onto their latent variables. The factor loadings are given in following Table 2. To establish discriminant and convergent validity CFA was performed using AMOS software. A 3 factor model was compared with a single factor forced model. Results indicate that three factor model had better fit " $\left(\chi^{2} / \mathrm{Df}=2.79 ; \mathrm{CFI} .=0.86\right.$; "GFI"= 0.80;"AGFI". = 0.75; NFI. = 0.79; RMSEA. = 0.09)" as compared to single factor model $"\left(\chi^{2} . / \mathrm{Df}=5.99 ; \mathrm{CFI} .=0.59 ; " \mathrm{GFI} "=0.58 ; “ \mathrm{AGFI} "=0.49 ; \mathrm{NFI} .=0.55 ; \mathrm{RMSEA} .=0.15\right)$.

Table 2. Measurement Models

\begin{tabular}{|l|l|l|l|l|l|l|l|l|}
\hline "Measurement Models" & $\boldsymbol{\chi}^{\mathbf{2}}$ & $\begin{array}{l}\text { Df" } \\
.\end{array}$ & $\boldsymbol{\chi}^{\mathbf{2}}$ (Df. & CFI. & GFI. & AGFI". & NFI." & RMSEA" \\
\hline $\begin{array}{l}\text { EL-MI-WI } \\
(\mathbf{3} \text { factor) }\end{array}$ & $\mathbf{6 6 2 . 2}$ & $\mathbf{2 3 7}$ & $\mathbf{2 . 7 9}$ & $\mathbf{0 . 8 6}$ & $\mathbf{0 . 8 0}$ & $\mathbf{0 . 7 5}$ & $\mathbf{0 . 7 9}$ & $\mathbf{0 . 0 9}$ \\
\hline $\begin{array}{l}\text { EL-MI-WI } \\
(\mathbf{1} \text { factor })\end{array}$ & 1451.1 & 242 & 5.99 & 0.59 & 0.58 & 0.49 & 0.55 & 0.15 \\
\hline
\end{tabular}

Note: Better fit indices are shown in bold."

\section{Descriptive Statistics}

Mean values along with Standard Deviations (SD) and correlation are presented in table 3. The mean value and $\mathrm{SD}$ for $\mathrm{EL}$ was $3.55(\mathrm{SD}=1.12)$; $3.37(\mathrm{SD}=1.467)$ for $\mathrm{MI}$ and $3.84(\mathrm{SD}=1.56)$ for WI.

\section{Correlation}

Correlation analysis provided initial support and directions for the proposed hypothesis. The results of correlation analysis revealed that Ethical Leadership (T1) has a positive correlation with Moral Identity $(\mathrm{T} 2)(\mathrm{r}=.30, \mathrm{p}<.001)$ and Whistleblowing intentions $(\mathrm{T} 3)(\mathrm{r}=.33, \mathrm{p}<$ $.001)$. 
Moreover, Moral identity has a significant positive correlation with whistleblowing intentions ( $\mathrm{r}$ $=.58, \mathrm{p}<.001)$. All the values for Pearson coefficient were in acceptable range i.e., $\mathrm{r}<0.7$ ensuring discriminant validity of the research article constructs.

Table 3. Correlation Analysis

\begin{tabular}{|l|lll|l|l|l|l|}
\hline \multicolumn{9}{|c}{ Mean } & S.D. & Gender & EL & MI & WI \\
\hline 1. & Gender & 1.61 & .487 & - & & & \\
\hline 2. & EL (Time 1) & 3.56 & 1.14 & -.08 & $\mathbf{( 0 . 8 4 )}$ & & \\
\hline 3. & MI (Time 2) & 3.37 & 1.48 & -.09 & $.30^{* *}$ & $\mathbf{( 0 . 9 2 )}$ & \\
\hline 4. & WI (Time 3) & 3.84 & 1.56 & -.18 & $.33^{* *}$ & $.58^{* *}$ & $\mathbf{( 0 . 8 9 )}$ \\
\hline
\end{tabular}

Note: N=213; Alpha Reliabilities are given in parentheses. EL= Ethical Leadership, MI= Moral identity, WI=Whistleblowing Intentions

${ }^{*}$ Correlation is significant at 0.05 level (2-tailed); ** Correlation is significant at the 0.01 level

\section{RESULTS}

Outcomes of this research article is being retrospection that the association between ethical leadership and whistleblowing intentions was also proved $(B=.58 ; p=0.000)$. Similarly, a positive and significant association was found between ethical leadership and moral identity $(\mathrm{B}=0.28$; $\mathrm{p}<0.000$ ). Moreover, a significant positive association was found between moral identity and whistleblowing intentions $(B=0.18 ; \mathrm{p}<0.01)$. In summary all direct effect hypothesis were proved.

The mediation hypothesis supported such that results of Sobel test show that moral identity mediates the positive relationship between ethical leadership and whistleblowing intention. The test of normal theory test highlights a significant mediation of moral identity $(B=.11 ; p<.05)$. Moreover, a non-zero value between upper and lower-level $\mathrm{CI}(0.01 ; 0.21)$ also support meditational role of moral identity between ethical leadership and whistleblowing intention. Since both Sobel test and Normal theory test are significant thus, we can infer the mediational role of moral identity between ethical leadership and whistle-blowing intentions.

These results are in line with previous researches which confirm that under supervision of ethical leaders employees feel empowered and psychologically secure such that they are willing to raise voice and speak against any ethical dilemma within their workplace, Chen and Hou (2016); Islam et al. (2019); Lam, Loi, Chan, and Liu (2016); Walumbwa and Schaubroeck (2009). The results suggest that ethical leaders' behaviours serve as a motivational source and support system that encourages employees to raise voice against any ethical odds within their workplace.

In similar vein, leaders have a significant influence on their subordinate's self-identity, Moore et al. (2019). These outcomes suggest that when employees work under an ethical leader, who actively engages and encourages ethical conduct of subordinates, then they begin to define themselves morally and ethically and their moral identity is shaped. In comparable vein, leaders are a source of influence for subordinates 'abilities, convictions and practices. Ethical leaders impact their ethical thinking which gives them fearlessness for detailing ethical problems (Whistleblowing), Liu et al. (2015) as they recognize the ethical dilemma and damages related with it, therefore they give importance to solving the issue and do not fear for the counter or negative results they may occur in wake of announcing it to respective authorities. 
Individual's personality is dynamic as it adapts as the circumstances change, Vallacher et al. (2005). Our investigation underpins the possibility that an ethical leader can impact a person's ethical self-idea for example moral identity and actuate certain part of one's ethical character which shape the consequent practices valuable for organizations and its employees (whistleblowing). Ethical leaders also create an ethical atmosphere within workplace which encourages the employees to raise voice against illegal and unethical practices taking place in the workplace, Kuenzi et al. (2020). Since a company's virtuous atmosphere verify that what ethical lead and practices are normal from workers in this way representatives shape their practices likewise, Singh et al. (1996). In this way heads of the organizations can keep up morals and implement ethical set of principles to make their employees ethical and courageous enough to speak up against ethical adversity.

\section{CONCLUSION}

Ethical leadership on employee whistleblowing intentions is playing a vital role in the organisation. The results of this research article highlight that ethical leaders encourage followers to blow the whistle when they witness any wrongdoing within their environment. Ethical leaders impact moral identity of their followers. The present research article has revealed a noteworthy positive relation between ethical leadership and moral identity of subordinates which specify that ethical leaders can shape identity of their subordinates. Moral identity encourage whistle blowing behaviour though whistle blowing intentions. The consequences again supported the idea that when individuals give importance to their moral identity then they are willing to blow the whistle in case of any ethical dilemma. The results also revealed that ethical leadership behaviours shape whistleblowing intentions of their subordinates by highlighting their moral identity. In other words, moral identity of subordinates mediates the relationship between ethical leadership and whistleblowing intentions.

\section{FINDINGS}

The aim of this research was to explore the influence of leader's ethical conduct on employee voicing behaviours i.e., whistle blowing intentions. Along with, this research also aimed at investigating the role that moral identity of follower's plays in shaping whistleblowing intentions and its mediation role in ethical leadership-whistleblowing intentions relationship. The data for the research article was gathered by employing a survey method and respondents rated their leader's ethical behaviour, their own moral identity and whistleblowing intentions at T1, T2, and T3 respectively. Where T1, T2 and T3 were one week apart. Majority of the respondents were females from service sector, working at different managerial levels in different departments. Results have proven that the associations previously hypothesized are true to a great extent. A total of four hypotheses were recommended, including three main effect hypotheses and one mediation hypotheses. The results fully supported the hypothesized relationships. The major findings of this research article are discussed below.

\section{REFERENCES}

Aquino, K., \& Reed, I. I. (2002). The self-importance of moral identity. Journal of personality and social psychology, 83(6), 14-23. 
Aquino, K., Freeman, D., Reed II, A., Lim, V. K., \& Felps, W. (2009). Testing a socialcognitive model of moral behaviour: the interactive influence of situations and moral identity centrality. Journal of Personality and Social Psychology, 97(1), 123-130.

Aquino, K., mcferran, B., \& Laven, M. (2011). Moral identity and the experience of moral elevation in response to acts of uncommon goodness. Journal of Personality and Social Psychology, 100(4), 703-707.

Bhal, K. T., Verma, M., Gupta, B., \& Dadhich, A. (2019, July). Ethical Leadership and Internal Whistle-Blowing: A Moderated Mediation Model. In Academy of Management Proceedings (Vol. 2019, No. 1, p. 16133). Briarcliff Manor, NY.

Brown, M. E., \& Treviño, L. K. (2006). Ethical leadership: A review and future directions. The Leadership Quarterly, 17(6), 595-616.

Callahan, E. S., \& Dworkin, T. M. (2000). The state of state whistle blower protection. Am. Bus. LJ, 38, 99-104.

Chen, A. S. Y., \& Hou, Y. H. (2016). The effects of ethical leadership, voice behaviour and climates for innovation on creativity: A moderated mediation examination. The Leadership Quarterly, 27(1), 1-13.

Chiu, R. K. (2002). Ethical judgement, locus of control, and whistleblowing intention: A case study of mainland Chinese MBA students. Managerial Auditing Journal, 23, 66-75.

Christensen-Salem, A., Walumbwa, F. O., Babalola, M. T., Guo, L., \& Misati, E. (2020). A multilevel analysis of the relationship between ethical leadership and ostracism: The roles of relational climate, employee mindfulness, and work unit structure. Journal of Business Ethics, 10, 1-20.

Dalton, D., \& Radtke, R. R. (2013). The joint effects of Machiavellianism and ethical environment on whistle-blowing. Journal of business ethics, 117(1), 153-172.

Ferreira, A. I. (2017). Leader and peer ethical behavior influences on job embeddedness. Journal of Leadership \& Organizational Studies, 24(3), 345-356.

Grojean, M. W., Resick, C. J., Dickson, M. W., \& Smith, D. B. (2004). Leaders, values, and organizational climate: Examining leadership strategies for establishing an organizational climate regarding ethics. Journal of business ethics, 55(3), 223-241.

Islam, T., Ahmed, I., \& Ali, G. (2019). Effects of ethical leadership on bullying and voice behaviour among nurses: mediating role of organizational identification, poor working condition and workload. Leadership in Health Services, 32(1), 2-17. 
Kuenzi, M., Mayer, D. M., \& Greenbaum, R. L. (2020). Creating an ethical organizational environment: The relationship between ethical leadership, ethical organizational climate, and unethical behavior. Personnel Psychology, 73(1), 43-71.

Lam, L. W., Loi, R., Chan, K. W., \& Liu, Y. (2016). Voice more and stay longer: How ethical leaders influence employee voice and exit intentions. Business Ethics Quarterly, 26(3), 277-300.

Lemoine, G. J., Hartnell, C. A., \& Leroy, H. (2019). Taking stock of moral approaches to leadership: An integrative review of ethical, authentic, and servant leadership. Academy of Management Annals, 13(1), 148-187.

Lewis, D. (2002). Whistleblowing procedures at work: what are the implications for human resource practitioners?. Business Ethics: A European review, 11(3), 202-209.

Liu, S. M., Liao, J. Q., \& Wei, H. (2015). Authentic leadership and whistleblowing: Mediating roles of psychological safety and personal identification. Journal of Business Ethics, 131(1), 107-119.

Mayer, D. M., Aquino, K., Greenbaum, R. L., \& Kuenzi, M. (2012). Who displays ethical leadership, and why does it matter? An examination of antecedents and consequences of ethical leadership. Academy of Management Journal, 55(1), 151-171.

Miceli, M. P., \& Near, J. P. (1985). Characteristics of organizational climate and perceived wrongdoing associated with whistle-blowing decisions. Personnel Psychology, 38(3), 525-544.

Moore, C., Mayer, D. M., Chiang, F. F., Crossley, C., Karlesky, M. J., \& Birtch, T. A. (2019). Leaders matter morally: The role of ethical leadership in shaping employee moral cognition and misconduct. Journal of Applied Psychology, 104(1), 123-132.

Wen, P., \& Chen, C. (2016). How does ethical leadership influence employees' whistleblowing intention? Evidence from China. Social Behavior and Personality: An International Journal, 44(8), 1255-1266.

O’Keefe, D. F., Messervey, D., \& Squires, E. C. (2018). Promoting ethical and prosocial behavior: The combined effect of ethical leadership and coworker ethicality. Ethics \& Behavior, 28(3), 235-260.

Ouakouak, M. L., Zaitouni, M. G., \& Arya, B. (2020). Ethical leadership, emotional leadership, and quitting intentions in public organizations. Leadership \& Organization Development Journal.

Park, H., \& Blenkinsopp, J. (2009). Whistleblowing as planned behavior-A survey of South Korean police officers. Journal of Business Ethics, 85(4), 545-556. 
Park, H., Blenkinsopp, J., Oktem, M. K., \& Omurgonulsen, U. (2008). Cultural orientation and attitudes toward different forms of whistleblowing: A comparison of South Korea, Turkey, and the UK. Journal of Business Ethics, 82(4), 929-939.

Patrick, R. B., Bodine, A. J., Gibbs, J. C., \& Basinger, K. S. (2018). What accounts for prosocial behavior? roles of moral identity, moral judgment, and self-efficacy beliefs. The Journal of Genetic Psychology, 179(5), 231-245.

Saha, R., Cerchione, R., Singh, R., \& Dahiya, R. (2019). Effect of ethical leadership and corporate social responsibility on firm performance: A systematic review. Corporate Social Responsibility and Environmental Management, 132-137.

Sharif, M. M., \& Scandura, T. A. (2014). Do perceptions of ethical conduct matter during organizational change? Ethical leadership and employee involvement. Journal of Business Ethics, 124(2), 185-196.

Singh, J., Verbeke, W., \& Rhoads, G. K. (1996). Do organizational practices matter in role stress processes? A study of direct and moderating effects for marketing-oriented boundary spanners. Journal of Marketing, 60(3), 69-86.

Tajfel, H., \& Turner, J. C. (1985). The social identity theory of intergroup behavior. In S. Worchel \& W. G. Austin (Eds.), Psychology of intergroup relations (2nd ed., pp. 7-24). Chicago: Nelson-Hall.

Tu, Y., Lu, X., Choi, J. N., \& Guo, W. (2019). Ethical leadership and team-level creativity: mediation of psychological safety climate and moderation of supervisor support for creativity. Journal of Business Ethics, 159(2), 551-565.

Vallacher, R. R., Nowak, A., \& Zochowski, M. (2005). Dynamics of social coordination: The synchronization of internal states in close relationships. Interaction Studies, 6(1), 35-52.

Walumbwa, F. O., \& Schaubroeck, J. (2009). Leader personality traits and employee voice behavior: mediating roles of ethical leadership and work group psychological safety. Journal of Applied Psychology, 94(5), 1275.

Yukl, G., \& Chavez, C. (2002). Influence tactics and leader effectiveness. Leadership, 139-165.

Zhou, H., Sheng, X., He, Y., \& Qian, X. (2020). Ethical Leadership as the Reliever of Frontline Service Employees' Emotional Exhaustion: A Moderated Mediation Model. International Journal of Environmental Research and Public Health, 17(3), 976987.

\section{Copyrights}

Copyright for this article is retained by the author(s), with first publication rights granted to the journal. This is an open-access article distributed under the terms and conditions of the Creative Commons Attribution license (https://creativecommons.org/licenses/by/4.0). 